\title{
Correction: Why Is Aging Conserved and What Can We Do about it?
}

\author{
Jason N. Pitt, Matt Kaeberlein
}

MK wishes to declare the following competing interest, which was omitted from the original article: MK is a founder of the Dog Aging Project, a University of Washington part-funded project that also solicits public donations through the University of Washington Foundation.

\section{Reference}

1. Pitt JN, Kaeberlein M (2015) Why Is Aging Conserved and What Can We Do about It? PLoS Biol 13(4): e1002131. doi:10.1371/journal.pbio.1002131 PMID: 25923592

\section{G. OPEN ACCESS}

Citation: Pitt JN, Kaeberlein M (2015) Correction: Why Is Aging Conserved and What Can We Do about it? PLoS Biol 13(5): e1002176. doi:10.1371/ journal.pbio.1002176

Published: May 15, 2015

Copyright: ๑ 2015 Pitt, Kaeberlein. This is an open access article distributed under the terms of the Creative Commons Attribution License, which permits unrestricted use, distribution, and reproduction in any medium, provided the original author and source are credited. 